\title{
Nickolai Nikolaevich Basargin (On His 80th Birthday)
}

DOI: $10.1134 / \mathrm{S} 1061934810110195$

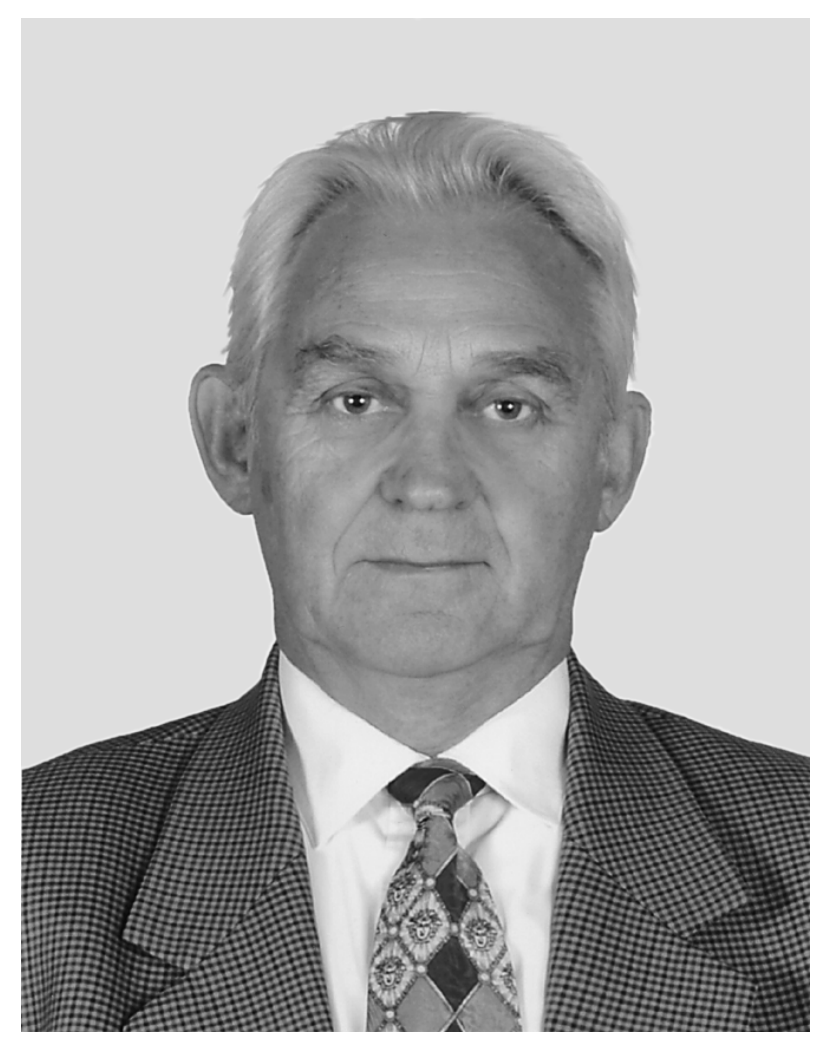

Nickolai Nikolaevich Basargin, Professor, Doctor of Chemistry, Honored Scientist of the Russian Federation, Chief Researcher of the Institute of Geology of Ore Deposits, Petrography, Mineralogy, and Geochemistry of the Russian Academy of Sciences, Veteran of the Second World War, celebrated his 80th birthday on July 27, 2010.

Professor Basargin is a well-known scientist fruitfully working in inorganic analysis. He made a significant contribution to the theory of the action and application of organic reagents and polymeric complexing adsorbents (PCA) in the analysis of minerals, rocks, ores, minerals, steels, alloys, and natural and sewage waters.
He has developed the theoretical basics and the methodology of revealing quantitative correlations between the physico-chemical properties of a reagent molecule, PCA, and the major analytical parameters of their complexes with different elements. The results of these studies are of interest for the prediction of the properties of reagents, adsorbents, and their complexes. Basargin has formulated, justified, and experimentally implemented a series of new approaches to the design of selective photometric reagents (bifunctional reagents with an intrinsic masking effect), discovered the laws of the effect of the electron nature of an element of cation and the acid-base properties of the reagent on selectivity of the analytical reaction. The analytical reagents (Nitchromazo, Carboxyarsenazo, Dichlorochromotropic acid, Arsenazokhimdu, Stilbazokhimdu, and others), polymeric complexing adsorbents, and analytical methods developed by Professor Basargin have found application in Russia; some reagents were included in the catalogues of foreign companies manufacturing reagents (England, Unites States, Germany, Japan, Poland, and Latvia).

Professor Basargin is the author of 480 publications in scientific journals, 43 inventor's certificates and patents, and 11 monographs; among his pupils are 42 candidates and 2 doctors of sciences. He is simultaneously Professor of the Divisions of Chemistry of Orel and Kursk Universities, where he delivers lecture courses on physico-chemical methods of analysis. He was a member of two dissertation councils, the Scientific Council on Analytical Methods at the Fedorovsky All-Russia Institute for Mineral Resources. Professor Basargin is member of the Scientific Council on Analytical Chemistry of the Russian Academy of Sciences, a member of a section of the editorial board of the journal Zavodskaya Labotatoriya. Diagnostika Materialov. He has state awards and the badge of an honored inventor of the USSR.

The staff of Zhurnal Analiticheskoi Khimii, colleagues, and friends congratulate Nickolai Nikolaevich Basargin on his 80th birthday and wish him good health and long years of creative activity. 